\title{
Revisiting the Linguistic Errors in the Writing of the Students Majoring in English
}

\author{
M. Asfah Rahman \\ Faculty of Language \\ Universitas Negeri Makassar \\ Makassar, South Sulawesi, Indonesia
}

\author{
Muhammad Nasiruddin Sainu \\ Faculty of Language \\ Universitas Negeri Makassar \\ Makassar, South Sulawesi, Indonesia
}

\author{
Indrawaty Asfah \\ Faculty of Language \\ Universitas Negeri Makassar \\ Makassar, South Sulawesi, Indonesia
}

\begin{abstract}
The basic writing skills ability of the students newly admitted to the English Department was still poor in terms of the grammatical aspect, choice and use of words, and phrase construction. This study reexamined the linguistic errors of the English Department students' writing. A total of 67 writing papers were randomly selected out of 125 writings of the 6th semester English Department students which were written in class in a 60-minute time. Their writings were then entered into word processing to identify the types of errors using the Linguistic Category Taxonomy. They were grouped into verb tenses, verb forms, modal auxiliary, sentence structure, word order, connectors, passive construction, subject-verb agreement, determiners, number, mechanics, dictions, preposition, and unclear ideas. Of 1080 sentences contained in students' writings, only 299 sentences $(27.69 \%)$ were grammatically correct. The most types of errors found were sentence structure $(20.71 \%)$, verb tense $(19.64 \%)$ and verb form $(15.64 \%)$. Other categories were less than $10 \%$. Of these errors, $\mathbf{6 2 . 2 9 \%}$ are attributable to intra-lingual transfer and $37.71 \%$ to inter-lingual transfer errors. These findings become the basis for designing and developing materials and strategies for writing course at the second years. The finding of this study may provide some guideline for the teachers in writing and grammar courses.
\end{abstract}

Keywords: linguistic error; writing English

\section{INTRODUCTION}

The study conducted by Rahman to determine the English language proficiency of the newly admitted students revealed that the English mastery level of the freshman majoring in English (which once regarded as the entry level knowledge) was only $45.31 \%$. Second, in generally, the basic elements of grammar were not yet mastered by the students [1]. Third, the level of language skills of new students majoring in English, in general, was still weak. Referring to Miller, this mastery level belongs to a frustrating level [2].

Yahrif reported the results of their study that one of the problems observed when the senior high school students were practicing making sentences was that the students always made grammatical mistakes and used inappropriate words [3]. For example, the word amount was used with a countable noun. Furthermore, the study also revealed that wrong word order was very often found, for example equipment school (supposedly: school equipment). In addition, the sentences often do not have a predicate (main verb), such as: "Although he poor, but him knowledge is rich" (which should be "Although he is poor, his knowledge is great").

\section{METHOD}

This descriptive study used essays written by students majoring in English Education who had passed Writing IV course. Three parallel classes (125 students) were assigned to write a narrative text in 60 minutes. Sixty-seven pieces of writing were randomly selected out of 125 writings as the research sample.

The process of analysis adhered the following steps (1) collection of a sample of language learner, (2) identification of errors, (3) description of errors, (4) explanation of errors, and (5) error evaluation. Error identification and description were carried out using linguistic category taxonomy, namely: verb tense, verb form, modal auxiliary, sentence structure, word order, connector, passive construction, subject-verb agreement, word form, articles, number, diction, mechanics, and unclear idea.

The taxonomy was used to identify the errors in each sentence of the students' essays, coded, and inputted into the computer using Microsoft Excel. This was used to compute the frequency and mean of the occurrence of each error category. Based on the taxonomy, each sentence of the essays was carefully examined to identify the error. A sentence might contain one or more errors.

\section{RESULTS}

\section{A. General Description of Students' Essays}

The total number of sentences in the 67 sample students' essays is 1080 sentences. Of these sentences, $781(72.31 \%)$ contain errors; thus, only 299 (27.69\%) are grammatically constructed. The number of sentences contained in each student's essay ranges from 4 to 39 sentences, or the average is 16.66 sentences. In average, the essays contained 241.46 words, and each sentence contained 16.44 words.

All essays contain at least four types of errors. There is even an essay that contains all 15 error categories. Most essays (38.81\%) contain 8 to 9 types of errors. There are $18(26.87 \%)$ essays that have more than ten error types (see Table 2). It is interesting that the students still made a variety of grammatical errors or ill-formed sentences when they are assigned to write. The students have taken three or four consecutive courses on 
the structure or explicit grammar and writing instruction for four semesters.

TABLE 1. Number of ERRor CATEgory by Number of EsSAys

\begin{tabular}{crc}
\hline \# of Error Categories & \# of Essays & \% \\
\hline 4 & 1 & 1.49 \\
5 & 6 & 8.96 \\
6 & 8 & 11.94 \\
7 & 8 & 11.94 \\
8 & 14 & 20.90 \\
9 & 12 & 17.91 \\
10 & 7 & 10.45 \\
11 & 7 & 10.45 \\
12 & 2 & 2.99 \\
13 & 1 & 1.49 \\
15 & 1 & 1.49 \\
\hline Total & $\mathbf{6 7}$ & $\mathbf{1 0 0}$ \\
\hline
\end{tabular}

It is surprising, and even challenging for grammar instruction, that some of the very basic English grammatical rules are still incorrectly constructed, for example, spelling rule like *english for English, *happyness for happiness, or *no thing for nothing. Figure 1 shows that almost all essays have errors of verb tense $(95.52 \%)$, verb form $(95.52 \%)$, and sentence structure (98.51). In other words, only about 3 (4.48\%) students who seem to have no problem with verb form and verb tenses. More strikingly is that only $1(1.49 \%)$ student whose essay does not contain sentence structure error. Other error categories which are found in more than $50 \%$ of the essays are word forms, diction, preposition, mechanics, and number.

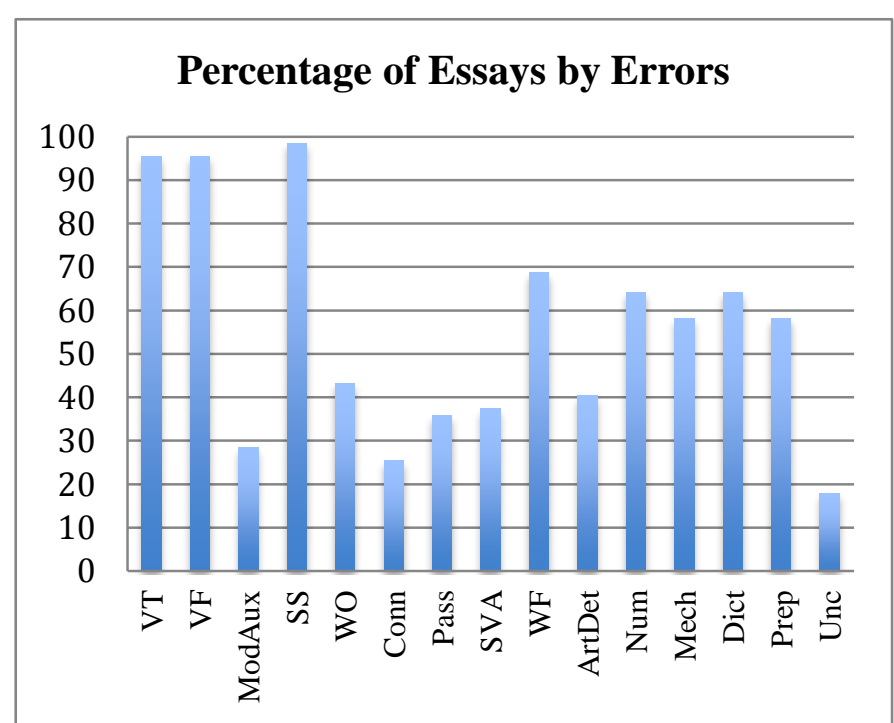

Fig. 1. Percentage of Essays by Error Category $(n=67)$

Table 2 shows an overview of all error categories in all students' essays. The total number of mistakes for each category is shown in frequency and percentage and ordered from the largest to the smallest in number. It can be seen that the greater number of errors is in the category of sentence structure or about $20.17 \%$ of a total number of mistakes, followed by tense verb category (19.64\%), dan verb form (15.64\%). The typical error in sentence structure category is the absence or omission of the verb which functions as the predicate. For examples, *The first day I like to study english when I in class X in senior high school. *The lessons in university almost about theories

TABLE 2. NUMBER OF LINGUISTIC ERRORS BY CATEGORY

\begin{tabular}{lcc}
\hline Category of Errors & Freq. & Percent \\
\hline SS (Sentence Structure) & 290 & 20.71 \\
VT (Verb Tense) & 275 & 19.64 \\
VF (Verb Form) & 219 & 15.64 \\
Mech (Mechanics: punctuation and & 91 & 6.5 \\
spelling) & & \\
WF (Word Form) & 89 & 6.36 \\
Dict (Diction or word choice) & 80 & 5.71 \\
Num (Countable and uncountable) & 75 & 5.36 \\
Prep (Prepositions) & 64 & 4.57 \\
ArtDet & 49 & 3.5 \\
(Article or Determiner) & 37 & 2.64 \\
WO (Word Order) & 36 & 2.57 \\
Pass (Passive Construction) & 35 & 2.5 \\
SVA & 24 & 1.71 \\
(Subject-Verb Agreement) & 23 & 1.64 \\
ModAux (Modal or Auxiliary) & & \\
Conn (Connector) & 13 & 0.93 \\
Unc (Unclear idea, translating from & & $\mathbf{1 0 0}$ \\
\hline native language) & $\mathbf{1 4 0 0}$ & \\
\hline TOTAL & & \\
\hline
\end{tabular}

. The other 13 error categories are less than $10 \%$ each.

\section{B. Error Description and Evaluation}

After identifying, classifying and counting the types of errors, it is important to explain and evaluate why the errors are made. This steps may reveal possible sources of errors which are classified into the interlingual transfer, intralingual negative transfer, the context of learning, and communication strategies [4].

\section{DISCUSSION}

The very high rate of errors in the students' essays, i.e. $72.31 \%$ of ungrammatical sentences, indicates that the essays would be rated poor regarding such components as language use, vocabulary, and mechanics [5]. The most frequent errors found in the students' writing are verb related errors, such as 
verb forms, tenses, and be as the main verb of a sentence. These types of errors have also been identified in college students' writing in the countries where English is taught as a foreign language, such as Thailand [6]-[10]. Although the order of error frequency for each category is relatively different as reported in these studies, one can draw a conclusion that writing instruction in English as a foreign language is very challenging once it comes to the appropriate use of the English grammatical rules including language use, mechanics, and vocabulary. The grammatical accuracy of the students' written products should always be dealt with and improved since it will certainly influence the readers' understanding of the messages or ideas expressed in the writing.

As discussed in the previous section, the source of the errors is mostly attributed to intralingual transfer. The students produce sentences which do not reflect the structure of their mother tongue, but do not either completely follow the English grammatical rules. The students might have mastered the rules partly and started to develop hypotheses that neither meet the rules the mother tongue nor the target language. The total number of intralingual transfer found in the essays was 872 which constitutes about $62.29 \%$ of the total number of errors. The rest $(37.71 \%)$ belong to interlingual transfer errors. This figure indicates that intralingual transfer errors are much higher than interlingual transfer errors. One possible explanation is that the students have already been exposed to explicit grammar instruction for four semesters in addition to four-semester course on writing. Unfortunately, their mastery of the English grammatical rules could not yet be completely applied when they are working on writing tasks. The mother tongue may come into play as a compensation strategy when the students are unable to retrieve the target language rules for immediate use.

The finding of this study may provide some guideline as to which grammar points the teachers should focus on for writing and grammar courses. Considering the frequency of the error occurrence, the teachers could focus more on sentence structures, verb tenses, and verb forms. These errors provide feedback as to the effectiveness of the teachers' teaching techniques and lead them to design and develop more appropriate exercises, practices, and assignments. For writing instruction, it is important to employ the writing process with more emphasis on the 'revising and editing' stages using such techniques as self-correction, peer-feedback, and teacher feedback.

\section{CONCLUSION}

The main objective of this study was to identify, classify, and describe the grammatical errors in essays composed by students of English as a foreign language at State University of Makassar. Based on the result of the data analysis presented in the previous sections, the following conclusions can be drawn. First, the students' essays contain ungrammatical sentences. In average, only around one-fourth of their sentences are appropriate, acceptable and error-free. Thus, about three-fourth of their sentences are not well-constructed or erroneous. The most frequent errors found in their essays are related to verbs, i.e. tenses, verb forms, and predicate. It indicates that quality of the students' essays, particularly the components of language use, vocabulary, and mechanics, is far from satisfactory.
Second, the grammatical errors that the students commit are due to intralingual and interlingual transfer. Intralingual transfer errors are much greater than interlingual transfer errors. Regardless of the source of errors, the high frequency of errors on sentence level will negatively influence the readers' understanding of the intended messages or ideas.

The findings in this study could have practical implication for grammar and writing instruction. Exposure to explicit grammar and writing instruction for around four semesters offered at the English Department at the University should first focus on mastery of verb related sentence construction, and then on other grammatical items such as word order, diction, and mechanics. When applying writing process approach in the writing instruction, emphasis should be given on the revising and editing stages by ways of self-revision, peer-revision or peer-feedback, and instructor feedback revision.

\section{REFERENCES}

[1] M. A. Rahman, 'GAMBARAN TINGKAT PENGUASAAN MATERI KURIKULUM BAHASA INGGRIS LULUSAN SEKOLAH MENENGAH UMUM DI SULAWESI SELATAN', Bhs. dan Seni, vol. 33, no. 1, 2009.

[2] W. H. Miller, 'Reading Diagnosis Kit.', 1974.

[3] M. Yahrif, 'USING JEOPARDY STRATEGY TO IMPROVE THE FIRST SEMESTER STUDENTS'VOCABULARY AT PIKIH PROGRAM OF UIN ALAUDDIN MAKASSAR 2014/2015', Dialekt. J. Pendidik. Bahasa, Sastra, dan Mat., vol. 1, no. 2, pp. 129-142, 2015.

[4] C. James, Errors in language learning and use: Exploring error analysis. Routledge, 2013.

[5] H. L. Jacobs, Testing ESL Composition: A Practical Approach. English Composition Program. ERIC, 1981.

[6] K. Nonkukhetkhong, 'Grammatical Error Analysis of the First Year English Major Students, Udon Thani Rajabhat University', in The Asian Conference on Language Learning 2013 Official Conference Proceedings, 2013, pp. 117-126.

[7] M. H. M. Sawalmeh, 'Error analysis of written English essays: The case of students of the preparatory year program in Saudi Arabia', English Specif. Purp. World, vol. 14, no. 40, pp. 1-17, 2013.

[8] I. Abushihab, 'An analysis of grammatical errors in writing made by Turkish learners of English as a foreign language', Int. J. Linguist., vol. 6, no. 4, p. 213, 2014.

[9] H. Tse and A. Yau, 'A Case Study of Grammatical Errors Made by Malaysian Students', Int. J. Sci. Commer. Humanit. Vol., no. 2, 2014.

[10] M. Q. Mohammed, 'Error Analysis: A Study on Grammatical Errors in the Writings of Iraqi EFL Learners. EUROPEAN ACADEMIC RESEARCH Vol. III, ISSN 2286-4822'. 2016. 